\title{
Potencial antimicrobiano dos óleos essenciais de cravo-da-índia (Syzygium aromaticum L.) e alfavacão (Ocimum gratissimum L.) em carne moída de ovinos contaminada experimentalmente com Staphylococcus aureus*
}

\section{Antimicrobial activity of essential oils of Syzygium aromaticum L. and Ocimumgratissimum L. in minced sheep meat experimentally infected with Staphylococcus aureus}

Anna Christina de Almeida, ${ }^{* *}$ Larissa de Oliveira, ${ }^{* * *}$ Paula Daiana de Paulo, ${ }^{* * * *}$ Ernane Ronie Martins, ${ }^{* * * * *}$ Rógerio Marcos de Souza, ${ }^{* \star * *}$ Lourdes da Silva de Figueiredo, ${ }^{* * * *}$ Claudinei Alves dos Santos, ${ }^{* * *}$ Hugo Calixto Fonseca******

\section{Resumo}

Avaliou-se o potencial antimicrobiano dos óleos essenciais de alfavacão (Ocimumgratissimum L.) e de cravo-da-índia (Syzygiumaromaticum L.) em carne moída de ovinos contaminadas experimentalmente com S. aureus ATCC 25923. Ambos os óleos em estudo foram utilizados na concentração de $400 \mu \mathrm{L} / \mathrm{g}$, e nos tempos de exposição de zero, cinco, 15 e 60 minutos. Os óleos essenciais analisados apresentaram atividade antimicrobiana na presença matriz alimentar utilizada. O óleo essencial do cravo-da índia apresentou maior efeito inibitório no tempo de 60 minutos em relação aos demais tratamentos ( $p \leq 0,001$ ), sugerindo que o aumento do tempo de exposição potencializou o efeito antimicrobiano.

Palavras-chave: Ocimumgratissimum L. e Syzygiumaromaticum L., condimentos, produtos naturais.

\begin{abstract}
The antimicrobial potential of the essential ails of alfavacão (Ocimum gratissimum L.) and indian clove (Syzygium aromaticum L.) were evaluated $i$ in minced sheep meat experimentally infected with S. aureus ATCC 25923 . Both of the oils under study were used study were used at a concentration of $400 \mathrm{microlitres} / \mathrm{g}$, and the exposure times were zero, five, 15 and 60 minutes. The essential oils analyzed showed antimicrobial activity in the presence of the food matrix used. The essential oil of Indian clove showed greater inhibitory effect on the time of 60 minutes compared to the treatments $(p \leq 0.001)$, suggesting that increasing the exposure time enhances the antimicrobial efficacy of the product.
\end{abstract}

Keywords: Ocimum gratissimum L., Syzygium aromaticumL., condiments, natural products.

\section{Introdução}

As indústrias alimentares e farmacêuticas demandam por uma busca contínua de novos e melhores agentes antimicrobianos, especialmente tendo em vista o aumento da resistência aos antibióticos convencionais. Uma das áreas de grande interesse é o uso de extratos de plantas e em particular os seus óleos essenciais, que além de possuírem atividades antimicrobianas, podem reduzir a expressão de fatores de virulência pelos microorganismos, como por exemplo, as enterotoxinas A e B e $\alpha$-toxina produzidas por S. aureus (Smith-Palmer et al., 2004).
Comparados ao uso de aditivos sintéticos, a utilização de plantas, especiarias, frutos e óleos essenciais com ação antimicrobiana ainda demandam pesquisas no que se refere aos seus efeitos na alimentação humana, ao odor marcante e ao alto custo para obtenção dos mesmos em escala comercial, conforme apresentado em uma ampla revisão literária descrita por Tajkarimiet al., (2010).

Tendo em vista a importância que a culinária utilizando carne de ovinos tem alcançado no país, pelas suas características nutricionais e políticas de incentivos à produção desta proteína

\footnotetext{
*Recebido em 12 de setembro de 2013 e aceito em 7 de janeiro de 2014.

**Instituto de Ciências Agrárias - Universidade Federal de Minas Gerais

${ }^{* * *}$ Mestre em Ciências Agrárias - Universidade Federal de Minas Gerais

****agrônoma - Universidade Federal de Minas Gerais

*****Docente da Universidade Federal de Minas Gerais

${ }^{* * * * * *}$ Engenheiro de Alimentos da Universidade Federal de Minas Gerais

E-mail para correspondência: aca2006@ica.ufmg.br
} 
de origem animal, e o uso de condimentos vegetais no processamento dos produtos, objetivou-se avaliar o potencial antimicrobiano dos óleos essenciais do Ocimum gratissimum L. (cravo-da-índia) e Syzygium aromaticumL. (alfavacão), em carne de ovinos contaminadas experimentalmente com $S$. aureus, visando o seu potencial uso futuro como conservantes.

\section{Material e métodos}

Para obtenção dos óleos essenciais em estudo utilizaram-se folhas frescas do alfavacão, e o botão floral seco do cravo-daíndia. A extração de ambos os óleos foi realizada pelo método de hidrodestilação utilizando-se o aparelho de Clevenger modificado (Pereira et al., 2008). Os óleos essenciais foram armazenados em frasco de vidro âmbar vedado e conservado a $-20^{\circ} \mathrm{C}$ até o momento das análises.

Amostras de carne de ovino foram adquiridas no comércio e, após a moagem em moedor estéril, realizou-se análise quanto à presença de $S$. aureus, em triplicatas foram separadas em quatro porções de $500 \mathrm{~g}$ cada, a serem submetidas aos diferentes tratamentos conforme descrito a seguir. Inóculos de S. aureus ATCC 25923 em dosagem de $10^{4}-10^{5} \mathrm{UFC} / \mathrm{g}$ foram preparados conforme recomendações de Barbosa et al., (2009) sendo estes utilizados para inoculação das amostras de carne moída em teste.

Soluções de óleo essencial de cravo-da-índia e de alfavacão foram preparadas considerando-se volumes do óleo para o peso de cada porção de carne a ser utilizada, obtendo-se as concentrações finais de $400 \mu \mathrm{L} / \mathrm{g}$. Estas concentrações foram definidas em estudos preliminares que determinaram a concentração inibitória mínima para cada óleo em teste frente à S.aureus (Oliveira, 2011).

Foram realizados quatro tratamentos utilizando-se carne moída contaminada com S. aureus e sem adição de produtos em teste, sendo o controle positivo (I); carne moída sem contaminação e sem a presença de óleos essenciais como controle negativo (II); carne moída contaminada e acrescido de óleo essencial de cravo-da-índia (Syzygiumaromaticum) (III) e carne moída contaminada e acrescido de óleo essencial de alfavacão (Ocimum gratissimum) (IV). Quatro porções de $50 \mathrm{~g}$ foram separadas em cada tratamento e nos controles, acondicionadas em embalagens estéreis e conservadas sob refrigeração por 60 minutos. Análises em duplicatas foram feitas nos tempos $0,5,15,60$ minutos de refrigeração, utilizando-se uma porção para cada tempo.

A efetividade dos óleos para redução da contaminação microbiana foi realizada de acordo com as recomendações da Portaria n. 101 do MAPA (Brasil, 1993). Diluições seriadas foram realizadas utilizando-se 1 grama de amostras de carne em $9 \mathrm{ml}$ de água peptonada estéril, obtendo-se diluições variando de $10^{-1}$ a $10^{-8}$. A partir das diluições, realizou-se contagem pour plate em Agar Baird Parker, incubado a $35^{\circ} \mathrm{C}$ por $24-48$ horas (Apha, 2001). Avaliação de características sensoriais relacionadas com as alterações na cor e odor foram realizadas a cada tempo de análise. Todo o procedimento foi realizado em condições controladas para evitar a contaminação cruzada.

O perfil fitoquímico dos óleos em estudo foi analisado segundo Matos (1997), para detecção da presença de metabólitos secundários taninos (reação de precipitação com cloreto férrico), caracterização de flavonoides (Shinoda, cloreto de alumínio, cloreto férrico e hidróxido de sódio), glicosídeos antraquinônicos (hidróxido de sódio) e alcaloides (reação com Dragendorff, Sheibler, Bouchardat, Bertrand e Mayer).

Análises foram realizadas comparando-se os quatro tempos dentro de cada um dos tratamentos. Os valores de significância e de coeficiente de variação foram obtidos convertendo-se os valores para Escala Logarítmica. As análises foram realizadas utilizando-se o pacote estatístico Sas (1997), por meio do PROC MEAN; PROC FREQ e PROC GLM.

\section{Resultados e discussão}

Os resultados referentes à redução de micro-organismos recuperados nas porções de carnes contaminadas após os referidos tempos de contato com as concentrações dos óleos estão apresentados na Tabela 1.

Tabela 1: Efeito do óleo essencial de cravo-da-índia e do óleo essencial de alfavacão na redução do crescimento bacteriano de $S$. aureus em carne moída de ovino

\begin{tabular}{lcccccc}
\hline & \multicolumn{5}{c}{$\begin{array}{c}\text { Log da contagem de micro-organismos } \\
\text { recuperados nos diferentes tempos de } \\
\text { contato (Minutos) }\end{array}$} \\
\cline { 2 - 6 } Óleo essencial & 0 & 5 & 15 & 60 & Média & CV \\
\hline Cravo-da-índia & $4,77^{\mathrm{B}}$ & $4,73^{\mathrm{B}}$ & $4,61^{\mathrm{B}}$ & $1,96^{\mathrm{A}}$ & $4,01^{\mathrm{a}}$ & 3,15 \\
Alfavação & $4,86^{\mathrm{B}}$ & $4,89^{\mathrm{B}}$ & $4,83^{\mathrm{B}}$ & $3,38^{\mathrm{A}}$ & $4,49^{\mathrm{b}}$ & 0,86 \\
\hline
\end{tabular}

Nota: Médias seguidas por letras maiúsculas na mesma linha não diferem pelo teste de Tukey $(p \leq 0,001)$. CV - coeficiente de variação.

O tempo de exposição de 60 minutos apresentou maior efeito em relação aos demais para ambos os tratamentos, sugerindo que o aumento do tempo de exposição potencializou o efeito antimicrobiano. O cravo-da-índia apresentou maior efeito na redução das contagens médias de micro-organismos.

Os melhores resultados de inibição, para $S$. aureus, foram atribuídos ao óleo de cravo-da-índia, sendo compatíveis com dados da literatura por Oussalah et al. (2007), Pereira et al. (2008) e Schereret al. (2009), porém todos estes estudos foram realizados em testes in vitro.

Quanto a estudos utilizando-se matrizes alimentares, Mendonça (2004) descreve resultados de atividade do óleo de cravo da índia frente a $S$. aureus inoculados em ricota cremosa, e Feniman (2011) estudou o efeito de óleo de cravo-da-índia sobre Lactobacillus rhamnosus e cultura starter em leite fermentado durante o período de shelf-life e ambos encontraram resultados que corroboram com os aqui obtidos. Barbosa et al. (2009) descreveram atividade de óleos essências obtidos de outras plantas sobre carne moída contaminada experimentalmente com patógenos alimentares, incluindo $S$. aureus e sobre a microbiota natural da carne. Os autores obtiveram resultados variáveis entre os diferentes óleos e bactérias Gram-positivas e Gram-negativas. No entanto, os resultados obtidos foram inferiores aos aqui encontrados, com valores de redução $1,3 \mathrm{e}$ 1,0 log ufc / g contra micro-organismos testados na inoculação experimental e na microbiota natural.

Observou-se a presença de taninos, taninos gálicos, flavonoides, glicosídeos antraquinônicos e alcaloides nos dois materiais vegetais em teste, podendo ser atribuído a estes o efeito 
antimicrobiano. O efeito biológico dos compostos fenólicos, como o eugenol, e das essências em geral é fácil ser observado nos experimentos, mas o mecanismo de ação ainda não é bem elucidado. Por via de regra, considera-se como início do mecanismo a degradação da parede celular, provocando danos à membrana proteica e citoplasmática, a interrupção da força motriz de prótons, o fluxo de elétrons e o transporte ativo, favorecendo a coagulação do citoplasma (Kotzekidouet al., 2008, Silva et al., 2010, Devi et al., 2010).

Testes in vitro têm identificado significantes atividades biológicas exibidas pelos polifenois como: ação bactericida, moluscida, anti-helmíntica e anti-hepatóxica; inibição da replicação do HIV; atividades antitumorais e inibição de enzimas. Estudos de toxicidade em relação a micro-organismos têm envolvido várias áreas de pesquisa como: farmacologia, nutrição, edafologia e fitopatologia. Dentre as hipóteses sobre os mecanismos da ação antimicrobiana dos taninos destacam-se a inibição de enzimas, a modificação do metabolismo celular pela atuação nas membranas e a complexação com íons metálicos com consequente diminuição da sua disponibilidade para o metabolismo dos micro-organismos (Mello e Santos, 2002).

A utilização de óleos essenciais para favorecer e alimentar é uma técnica viável, uma vez que a concentração capaz de impedir o crescimento microbiano seja determinada (Goñi et al., 2009). No entanto, está susceptível à modificação da natureza do efeito inibitório na presença de alterações da matriz alimentar (Holley e Patel, 2005), comprometendo a qualidade microbiológica do produto. Smith-Palmer et al. (2001) evidenciaram que concentrações de 0,5 e $1 \%$ desses óleos são necessárias para inibir com êxito a contaminação de alimentos. Além disso, o uso de concentrações insuficientes permitirá o restabelecimento de células injuriadas não letalmente. A composição química, em relação à gordura, da matriz alimentar mostrou ser um importante fator na determinação da eficiência dos óleos testados.

Os dados obtidos evidenciam a necessidade de pesquisas mais aprofundadas para se avaliar o potencial destes condimentos como conservantes alimentares, além de se elucidar as interações entre os componentes dos óleos essenciais com matrizes alimentares, bem como a estabilidade e interferência dos mesmos nas características sensoriais durante o processamento.

\section{Conclusão}

O óleo essencial de cravo-da-índia e de alfavacão apresentaram atividade antimicrobiana na presença de carne de ovino.

O óleo essencial de cravo-da-índia apresentou maior atividade antimicrobiana em comparação ao óleo essencial de alfavacão.

O tempo de exposição potencializou a atividade antimicrobiana dos dois óleos essenciais em estudo.

\section{Agradecimentos}

Ao Banco do Nordeste do Brasil - Projeto BNB/FUNDECI 2009.005, à FAPEMIG pela bolsa de mestrado, à PRPq/FAPEMIG pela bolsa e recursos Edital BITIB/2010.

\section{Referências}

AMERICAN PUBLIC HEALTH ASSOCIATION.Compendium of methods for the microbiological examination of foods.4th ed. Washington: APHA, 2001. 676 p.

BARBOSA, L.N., RALL, V,L, FERNANDES, A.A., USHIMARU, P.I., SILVA PROBST, I., FERNANDES, A. JR. Essential Oils Against Foodborne Pathogens and Spoilage Bacteria in Minced Meat. Foodborne Pathogens and Dieases v. 6, n. 6, p. 725-728, 2009.

BRASIL.Ministério da Agricultura, Pecuária e Abastecimento. Portaria n. 101, de 17 de agosto de 1993. Métodos de Análise Microbiológica para Alimentos. Diário Oficial da União, Brasília: Poder Executivo, 17 de ago. 1993, Seção I,p. 11937.

DEVI, K.P., S.A. NISHA, R. SAKTHIVEL, AND S.K. PANDIAN. Eugenol (an essential oil of clove) acts as an antibacterial agent against Salmonella typhi by disrupting the cellular membrane. Journal of Ethnopharmacology, v.130. n. 1, p. 107-115, 2010.

FENIMAN, M.C. Potencialização de óleos essenciais como antimicrobianos aplicados em produtos lácteos fermentados. 2011. 97 p.Tese de Doutorado. Programa de Pós-graduação em Biologia Geral e Aplicada, Universidade Estadual Paulista.

GOÑI, P., LÓPEZ, P., SÁNCHEZ, C., GÓMEZ-LUS, R., BECERRIL, R., NERÍN, C. Antimicrobial activity in the vapour phase of a combination of cinnamon and clove essential oils. Food Chemistry, v. 116, p. $982-989,2009$.
HOLLEY, R. A., PATEL, D. Improvement in shelf-life and safety of perishable foods by plant essential oils and smoke antimicrobials. Food Microbiology, v. 22, p. 273-292, 2005.

KOTZEKIDOU, P., GIANNAKIDIS, P., BOULAMATSIS, A. Antimicrobial activity of some plant extracts and essential oils against foodborne pathogens in vitro and on the fate of inoculated pathogens in chocolate. LWT, v. 41, p. 119-127, 2008.

MATOS, F.J.A. Introdução a Fitoquímica Experimental, Fortaleza: EUFC, 1997.

MELLO, C. P., SANTOS, S. C. Taninos. In: Farmacognosia: da planta ao medicamento. Organizadopor Cláudia Maria Oliveira Simões et al. 4. ed. Porto Alegre / Florianópolis: Editora Universitária / UFRGS / Ed. da UFSC, 2002. 950 p.

MENDONÇA, A. T. Efeito dos óleos essenciais de condimentos sobre o crescimento deStaphylococcus aureus em ricota cremosa. 2004. 72 p. Tese de Doutorado. Programa de Pós-graduação em Ciências de Alimentos. Universidade Federal de Lavras.

OLIVEIRA, L. Efeito inibitório dos óleos essenciais de alfavacão (Ocimum gratissimuml.) e cravo-da-índia (Syzygium aromaticuml.) e do suco de limão (citruslatifoliatanaka) frente às bactérias Staphylococcus aureus e Escherichia coli isoladas de carcaças de ovinos. 2011. 97 p. Dissertação de Mestrado. Programa de Pósgraduação em Ciências Agrárias. Universidade Federal de Minas Gerais. 
OUSSALAH, M., CAILLET, S., SAUCIER, L., LACROIX, M. Inhibitory effects of selected plant essential oils on the growth of four pathogenic bacteria: E. coli O157:H7, Salmonella Typhimurium, Staphylococcus aureusand Listeria monocytogenes. Food Control, v. 18, p. 414-420, 2007.

PEREIRA, A. A.,CARDOSO, M. G., ABREU, L. R. A., MORAIS, A. R., GUIMARÃES, L. G. L., SALGADO, A. P. S. P. Caracterização química e efeito inibitório de óleos essenciais sobre o crescimento de Staphylococcus aureus e Escherichia coli. Ciência e Agrotecnologia. v. 32, n. 3, p. 887-893, 2008.

SCHERER, R., WAGNER, R., DUARTE, M. C. T., GODOY, H. T. Composição e atividades antioxidante e antimicrobiana dos óleos essenciais de cravo-da-índia, citronela e palma rosa. Revista Brasileira de Plantas Medicinais. v. 11, n. 4, p. 442-449, 2009.

SILVA, L. L.,HELDWEIN, C. G., REETZ, L. G. B., HÖRNER, R., MALLMANN, C. A., HEINZMANN, B. M. Composição química, atividade antibacteriana in vitro e toxicidade em Artemia salina do óleo essencial das inflorescências de Ocimum gratissimum L., Lamiaceae. Revista Brasileira de Farmacognosia, v. 20, n. 5, p. 700-705, 2010.
SMITH-PALMER, A., STEWAR, J., FYFE, L.The potential application of plant essential oils asnatural food preservatives in soft cheese. Food Microbiology, 18, p. 463-470, 2001.

SMITH-PALMER, A., STEWAR, J., FYFE, L. Influence of subinhibitory concentrations of plant essential oils on the production of enterotoxins $A$ and $B$ and $\alpha$-toxin by Staphylococcus aureus. Journal of Medical Microbiology v. 53, 1023-1027.2004.

STATISTICAL ANALYSIS SYSTEM. SAS Institute inc., SAS/STAT. User's guide, version 6.11. 4. ed. Cary: SAS Institute inc., 1997. 842 p.

TAJKARIMI, M. M., IBRAHIM, S. A., CLIVER, D.O. Antimicrobial herb and spice compounds in food. Food Control, v. 21, p. 11991218, 2010. 